Int. J. Dev. Biol. 58: 601-611 (2014)

doi: $10.1387 / \mathrm{ijdb} .140136 \mathrm{rc}$

\title{
The development of viable and nutritive embryos in the direct developing gastropod Crepidula navicella
}

\author{
MARYNA P. LESOWAY ${ }^{1,2}$, EHAB ABOUHEIF*,1 and RACHEL COLLIN ${ }^{*, 2}$ \\ ${ }^{1}$ McGill University, Montreal, QC, Canada and ${ }^{2}$ Smithsonian Tropical Research Institute, Balboa, Ancon, Republic of Panama
}

\begin{abstract}
Adelphophagy occurs when encapsulated embryos complete development by feeding on their developing siblings, which are known as nutritive embryos. Nutritive embryos are found in a variety of animal groups, and are especially common in some groups of marine invertebrates. Although they have evolved numerous times independently in the calyptraeid gastropods, adelphophagic development with nutritive embryos has not been described in detail. Using light microscopy and time-lapse imaging of laboratory-reared embryos, we describe the development of Crepidula navicella, a direct developer with nutritive embryos that cleave and gastrulate. Early stages of nutritive and viable embryos do not show any obvious morphological differences, but do show asynchrony in early cleavage among embryos from the same capsule. We discovered that two classes of nutritive embryos are produced; gastrula-like nutritive embryos, which arrest after gastrulation, and post-gastrula-like nutritive embryos that are more variable in morphology, and show evidence of minor differentiation. This study provides a framework for future research on the developmental and molecular mechanisms of nutritive embryo development of $C$. navicella, which will allow us to address the role of nutritive embryos in the origins of developmental polyphenisms. Careful description of the developmental sequence is necessary before adaptive hypotheses can be addressed, and comparisons with other taxa can be made. Understanding the different ways that embryos and their development are disrupted to produce nutritive embryos will provide important insights into the normal process of development.
\end{abstract}

KEY WORDS: developmental timeline, adelphophagy, nutritive embryos, nurse eggs, trophic eggs

\section{Introduction}

Maternal provisioning of supernumerary eggs and embryos for consumption by viable siblings is termed oophagy in the case where uncleaved eggs are consumed, or adelphophagy when cleaving embryos or later developmental stages are consumed. Oophagy and adelphophagy are phylogenetically widespread and have been reported in such diverse groups as arachnids, social and non-social insects, fish, frogs, and marine invertebrates including polychaetes and gastropods (Elgar and Crespi 1992; Perry and Roitberg 2006). This strategy is common in marine invertebrates, where large numbers of embryos are deposited within an egg capsule and only a subset develops to hatching (Thorson 1950; Fioroni 1988). Although these are often referred to as nurse eggs in the marine invertebrate literature, or trophic eggs in the terrestrial invertebrate literature, here we will refer to these excess embryos as "nutritive embryos". The term nutritive embryos highlights their functional role and avoids confusion with the term "nurse cells", which contribute to germ cell production in insects (Gilbert 2006). In spite of the widespread presence and general interest in adelphophagy, little is known about the evolutionary and developmental basis of nutritive embryos. Nutritive embryos have likely evolved to provide nourishment for developing embryos or to reduce brood competition in the form of sibling cannibalism. Alternatively, they do not serve an adaptive nutritive function and are failed eggs that are either non-fertilized or abnormally developing (Perry and Roitberg 2006). Therefore, we must describe the development of viable and nutritive embryos to distinguish between these possibilities. This will allow us to use the differences in developmental mechanisms differentiating viable embryos from nutritive embryos to gain insight into the regulation of normal development, to determine whether nutritive embryos are an alternative developmental phenotype, and to ask further questions about the evolutionary origins, potential adaptive roles, and developmental and molecular mechanisms leading to the production of nutritive embryos.

Development of nutritive embryos in gastropods is known mainly

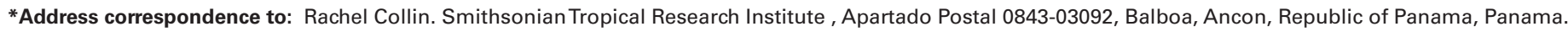

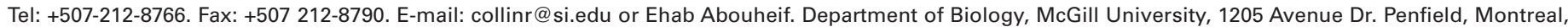
OC, Canada, H3A-1B1.Tel: +1-514-398-7190. Fax: +1-514-398-5069. e-mail: ehab.abouheif@mcgill.ca
} 
from non-cleaving nutritive eggs or from nutritive embryos that arrest development after a few abnormal cleavages (Rivest 1983; West 1983; Gallardo and Garrido 1987; Stöckmann-Bosbach 1988; Calvo and Templado 2004; Güler and Lök 2013; Smith and Thatje 2013). Several types of nutritive embryos have evolved multiple times independently in at least 5 genera of the calyptraeid gastropods (Collin 2004). For example, in Crepipatella dilatata, nutritive eggs do not cleave (Gallardo 1977; Gallardo and Garrido 1987), whereas in Crepidula navicella, Crepidula coquimbensis and Crepipatella occultanutritive embryos cleave and gastrulate (Collin 2003a; Veliz et al., 2003; Collin 2004; Collin et al., 2007; Veliz et al., 2012). Few details of the development of gastrulating nutritive embryos have been published to date (Fioroni 1988; Collin 2003a).

This variety of observed patterns of nutritive embryo morphologies is likely the result of a diversity of developmental processes, although mechanisms are poorly characterized. In many cases, non-fertilized eggs are provisioned as nutritive eggs, as in frogs (Gibson et al., 2004). Non-cleaving nutritive eggs of $C$. dilatata are also likely unfertilized (Gallardo and Garrido 1987). In ants, both queens and sterile workers produce two types of unfertilized eggs: viable male embryos that localize key maternal determinants to the posterior pole within the embryo and fat-filled trophic eggs that do not localize these same determinants (Khila and Abouheif 2008, 2010). Fertilization of eggs by abnormal sperm is unlikely as a mechanism based on sperm ultrastructure (Gallardo and Garrido 1987, West 1983). Nutritive embryos of the spionid polychates, Polydora cornuta and Boccardia proboscoidea, have been shown to develop via apoptosis, a developmental process in which cell death can play an active degenerative role (Smith and Gibson 1999; Gibson et al., 2012).

Here, we describe in detail the development of Crepidula navicella, a direct developer that feeds on cleaving, gastrulating, nutritive embryos during the course of development. As a congener with the spiralian model species, Crepidula fornicata,
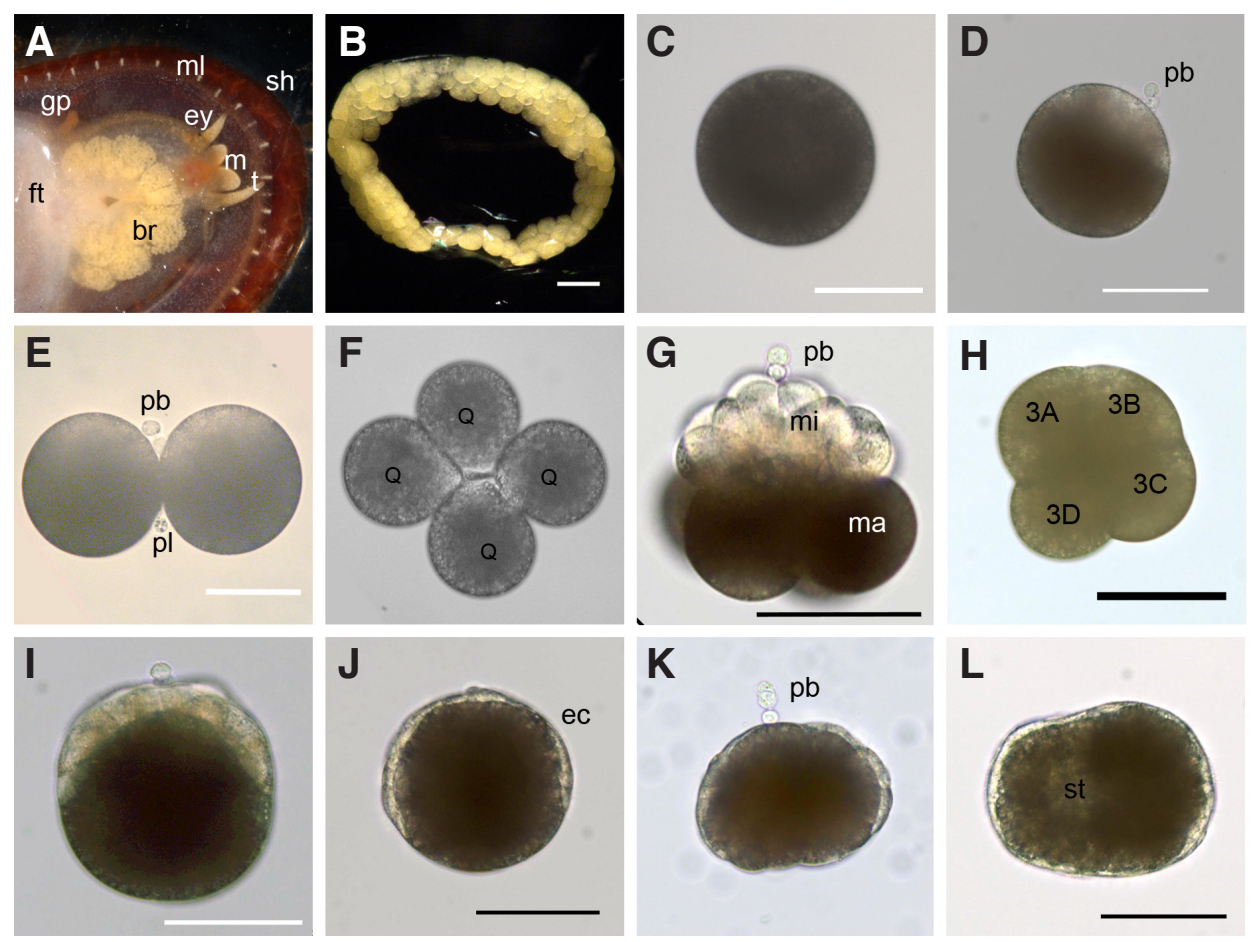

studies of $C$. navicella will be able to take advantage of the tools becoming available for $C$. fornicata, including microinjection, in situ hybridization, and functional assays (Henry et al., 2010a). C. navicella is also the sister species of Crepidula onyx, which may have re-evolved indirect development with a swimming, feeding (planktotrophic) larva (Collin 2004). In fact, the three calyptraeids where topography of the phylogenetic tree suggests that planktotrophy may have re-evolved all have adelphophagic sister species (Collin 2004). The presence of adelphophagy in close relation with possible instances of re-evolution of planktotrophy suggests that nutritive embryo production is not simply a neutral degeneration or non-adaptive loss of function, but rather, allows for retention of important developmental characters, which include a functional velum, such that planktotrophy could re-evolve once lost. This is in contrast to direct development from large eggs, which appears to be phylogenetically constrained and does not lead to re-evolution of planktotrophy (Collin 2004). In this context, nutritive embryos could be considered as an alternative developmental phenotype that would permit such evolutionary reversals. Describing the patterns of nutritive embryo development in the calyptraeid gastropods will therefore provide a valuable point of comparison not only with other adelphophagic developers, but more broadly, with other polyphenic taxa. Additionally, development of nutritive embryos and the ways in which their development is disrupted will provide a better understanding of how normal development functions, as well as providing a framework for interpreting further investigation of the developmental and molecular basis for development in this system.

\section{Results}

\section{Laying}

In the lab, females of Crepidula navicella lay 16 capsules on average (range $=8$ to 28 capsules, mean $=16.03$ capsules \pm 4.5 $\mathrm{SD} ; \mathrm{n}=60$ broods from 15 females), each containing an average

Fig. 1. Early development of viable and nutritive embryos of $\boldsymbol{C}$. navicella. Females brood (A) multiple capsules. Each capsule (B) contains approximately 150 embryos, laid in the primary oocyte stage. Embryos then (C) complete meiosis, producing (D) polar bodies. Polar lobes are extruded before (E) first cleavage (lateral view) and (F) second cleavage (vegetal view). Further cleavages produce large yolky macromeres at the vegetal pole and clear micromeres at the animal pole, clearly seen at the (G) 20-cell stage (lateral view). At the $\mathbf{( H )} 24-c e l l ~ s t a g e$ (animal view), the D-quadrant micromere, the $3 D$ cell, protrudes prior to cleavage of the $4 d$ mesentoblast. Cleavage continues, producing a (I) blastula-stage embryo (lateral view). The large, yolky macromeres are then engulfed by epithelial cells via epiboly, leading to a (J) gastrula-stage embryo (lateral view). The gastula later (K) invaginates to form the stomodeum. Gastrula continue to (L) elongate (animal view), and the stomodeum is seen here as a clearing towards the anterior (left) side. br, brood; ec, ectoderm; ey, eye; ft, foot; gp, genital papilla; $m$, mouth; ma, macromere; mi, micromere; $\mathrm{ml}$, mantle; pb, polar body; pl, polar lobe; sh, shell; st, stomodeum; t, tentacle. Scale bars, 100 $\mathrm{m}$. 
TABLE 1

\section{TIMING OF CLEAVAGES OF C. NAVICELLA AT $28^{\circ} \mathrm{C}$}

\begin{tabular}{|c|c|}
\hline Time & Stage \\
\hline \multirow[t]{3}{*}{ Laying } & $\begin{array}{l}\text { Germinal vesicle } \\
\text { Laying takes place over the course of several hours, capsule formation takes } \\
\text { roughly } 20-30 \text { minutes. }\end{array}$ \\
\hline & First polar body \\
\hline & $\begin{array}{l}\text { Second polar body } \\
\text { Following formation of polar bodies, pronuclear fusion occurs. }\end{array}$ \\
\hline Oh & 2-cell; first cleavage (holoblastic and essentially equal with small polar lobe) \\
\hline $2 \mathrm{~h} 10 \mathrm{~min}$ & 4-cell; second cleavage (holoblastic and essentially equal with small polar lobe) \\
\hline 4h5min & $\begin{array}{l}\text { 8-cell; third cleavage forms first quartet micromeres, spiral cleavage obvious, polar } \\
\text { lobe not noted }\end{array}$ \\
\hline $6 \mathrm{~h} 10 \mathrm{~min}$ & 12-cell; formation of second quartet micromeres \\
\hline $8 \mathrm{~h} 20 \mathrm{~min}$ & 20-cell; third quartet formed \\
\hline $9 \mathrm{~h} 40 \mathrm{~min}$ & 24-cell; extrusion of 3D macromere prior to cleavage \\
\hline $11 \mathrm{~h} 45 \mathrm{~min}$ & 25-cell; 4d mesentoblast forms \\
\hline
\end{tabular}

of 150 embryos (range $=57$ to 243 embryos per capsule, mean $=151.84$ embryos per capsule $\pm 32.4 \mathrm{SD}, \mathrm{n}=68$ capsules from 17 females), similar to numbers reported by Collin and Spangler (2012) (mean capsule number $=13.63$, mean eggs $/$ capsule $=139$ at $23^{\circ} \mathrm{C}$; mean capsule number $=12.11$, eggs $/$ capsule $=119$ at $28^{\circ} \mathrm{C}$ ). Embryos, albumen, and capsular material are passed from the genital papilla, to the foot, and on to the propodium, which the females use to shape and fasten the capsules to the substrate. Teardrop-shaped capsules are joined via a strand to the substrate at a common point, as described by Hoagland (1986). Females hold the brood in the space between the head, foot, and substrate, just below the neck (Fig. 1A). Capsules are initially very sticky, but solidify by the time of first cleavage. In the lab, females can lay at any time of day, but frequently begin laying in the evenings. Production of a full clutch takes several hours, and females produce one capsule roughly every twenty to thirty minutes. If disturbed, females continue to lay eggs when re-attached to the substrate until the brood is complete. If the brood is removed from the female before brood development is complete, females do not replace them immediately.

Large numbers of nutritive embryos are apportioned to each capsule. Of the approximately 150 embryos per capsule, only $7 \%$ of all embryos in a capsule are viable (range $=4$ to 21 viable embryos, mean $=10.67$ viable embryos per capsule, $S D=4.04$, $\mathrm{n}=68$ capsules from 18 females). Early development is the same for all embryos (Fig. 1), and it is not until the anlagen of structures such as the foot, shell, and head vesicle, are visible that viable embryos can be reliably differentiated from nutritive embryos using light microscopy. Nutritive embryos arrest development prior to this point, either as gastrula-like nutritive embryos, or slightly later as post-gastrula-like nutritive embryos. Nutritive embryo types are described in detail below.

\section{Early development}

Embryos of $C$. navicella exhibit a typical spiral cleavage pattern as reported for C. fornicata (Conklin 1897; Hejnol et al., 2007; Henry and Perry 2008; Henry et al., 2010a). A timeline of cleavage is found in Table 1. Eggs are laid at the primary oocyte stage and are somewhat flattened in shape, but become rounded as meiosis resumes (Fig. 1B-C). Average egg diameter is $161 \mu \mathrm{m}$ $($ range $=149.76$ to $181.45 \mu \mathrm{m}$, mean $=161.11 \mu \mathrm{m} \pm 6.20 \mathrm{SD}, \mathrm{n}=$
56 eggs from one female), similar to egg sizes reported by Collin and Spangler (2012) (mean $=156.89 \mu \mathrm{m}$ for 22 females and 1241 eggs at $23^{\circ} \mathrm{C}$; and mean $=158.62 \mu \mathrm{m}$ for 16 females and 695 eggs at $28^{\circ} \mathrm{C}$ ). Meiosis completes prior to first cleavage, producing two polar bodies at the animal pole of the embryo (Fig. 1D). First and second cleavages are equal and holoblastic (Fig. $1 \mathrm{E}-\mathrm{F}$ ). These cleavages are preceded by the extrusion of a small polar lobe at the vegetal pole of the embryo, which contains granules of unknown material (Fig. 1E). The third cleavage forms the first quartet of micromeres, which contain little to no yolk (Fig. 1G). All embryos cleave normally, and there are no obvious morphological differences between nutritive and viable embryos during early cleavage. This includes the extrusion of the 3D macromere at the 24-cell stage prior to the precocious cleavage of the $4 \mathrm{~d}$ mesentoblast (Fig. $1 \mathrm{H}$ ). Fewer than $1 \%$ of embryos are abnormal from the beginning of development and either do not cleave or cleave abnormally. This is considered normal for non-adelphophagic calyptraeids (Conklin 1897) and will not be considered further here.

Gastrulation proceeds via epiboly; micromeres migrate to surround the large, yolky macromeres (Fig. $1 \mathrm{~J}-\mathrm{K}$ ). Gastrulae then compress and invaginate to form the stomodeum, (Fig. $1 \mathrm{~K}-\mathrm{L}$ ). It is at this stage that ciliation is first visible, but embryos do not begin to move freely within the capsule until slightly later. Embryos continue to elongate in the anterior-posterior direction as the stomodeum forms (Fig. 1L).

Later development of viable embryos and feeding behaviour

Development within the capsule is similar to that reported for other calyptraeids (Table 2). Using a light microscope, viable em-
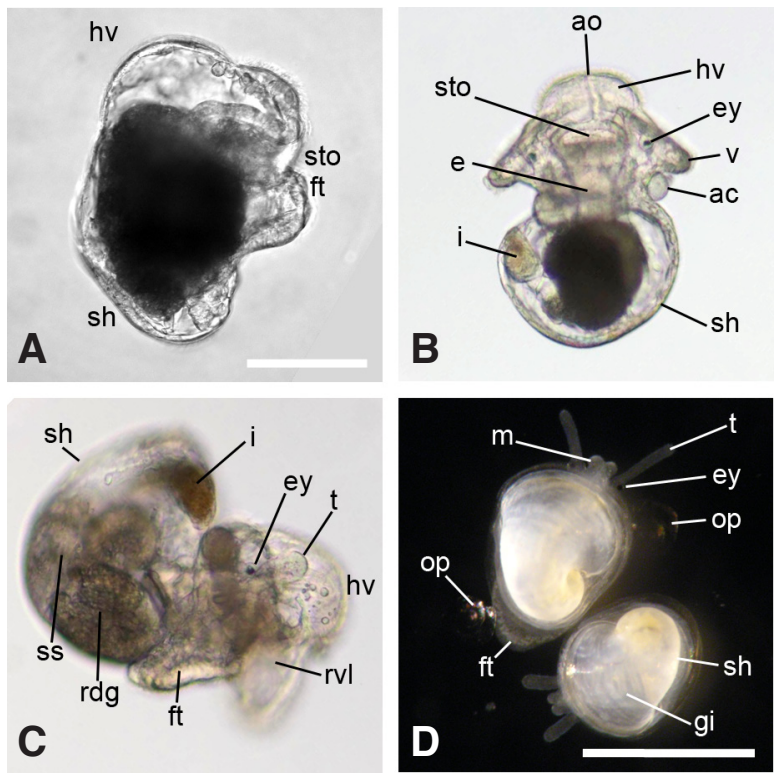

Fig. 2. Late development of viable embryos of C. navicella. Development progresses through (A) pre-veliger stage (right lateral view), (B) early-veliger stage (ventral view), (C) veliger-stage (right lateral view), and finally following an intra-capuslar metamorphosis (D) the juvenile stage (dorsal view, scale bar $1 \mathrm{~mm}$ ). ac, absorptive cell; ao, apical organ; e, esophagus; ey, eyespot; ft, foot; gi, gill; hv, head vesicle; $i$, intestine, $m$, mouth; op, operculum; rdg, right digestive gland; rvl, right velar lobe sh, shell; ss, style sac; sto, stomodeum; t, tentacle; v, velum. Scale bars, $100 \mu \mathrm{m}$ where not indicated. 

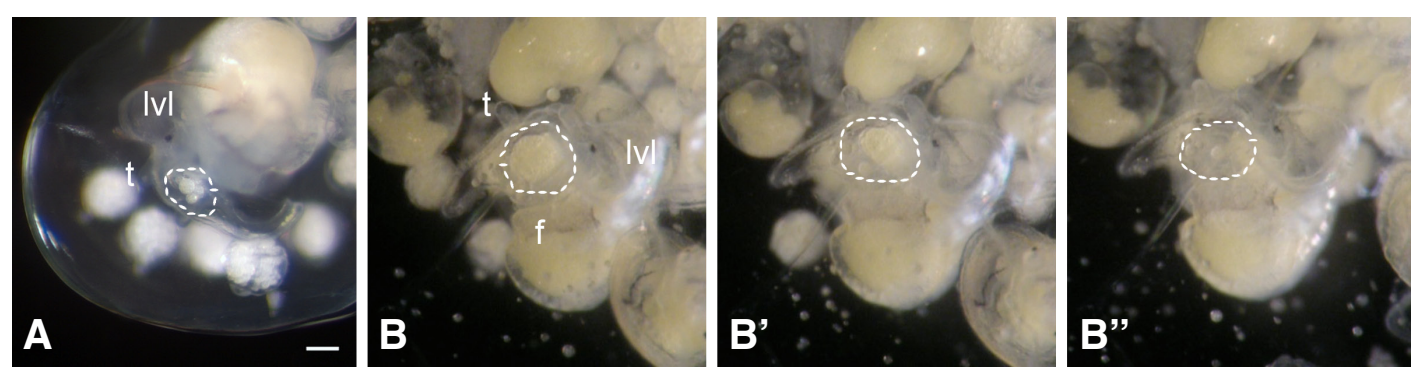

Fig. 3. Intracapsular feeding in late veliger-stage embryos of $\boldsymbol{C}$. navicella. Late-veliger embryos consume nutritive embryos in the form of yolk granules (A) captured by the velar cilia or whole nutritive embryos (B-B"). Sequence of images in (B) taken from video. Dashed lines surround the mouth opening. f, foot; $t$, tentacle; IVl, left velar lobe. Scale bar, 100um. bryos can only be reliably distinguished from nutritive embryos when the foot, shell and head vesicle anlagen become visible (Fig. $2 \mathrm{~A}$ ), approximately 7-8 days after being laid. Yolk particles can be seen in the stomodeum shortly after this and ingestion of yolk particles begins in earnest by day 9 . As viable embryos progress into early veliger-stage embryos at approximately 9 days (Fig. 2B), they show a large head vesicle and stomodeum, as well as velar lobes, large absorptive cells of the embryonic kidneys, eyespots, apical organ, a cup-shaped shell and digestive tract. By day 15, viable embryos continue to ingest particles of yolk from degraded nutritive embryos, and are also capable of ingesting whole nutritive embryos (Fig. 3). At this point, the digestive tract is well developed, and viable embryos have increased greatly in size and the head vesicle is prominent (Fig. $2 \mathrm{C}$ ).

The shell begins to develop as a cap over the ectoderm around day 9 , and coils over the embryo. As development progresses within the capsule, the rim of the coiled protoconch expands to form a brim so that by hatching the typical limpet-like shell is present. The larval heart is prominent as the embryo develops, and pumps visibly anterior to the shell, until the shell overgrows it. Embryos are unable to retract fully into the shell, and will not do so even when gently prodded with a probe.

The velum is ciliated, with prominent prototrochal cilia. Metatrochal cilia and a food groove are also present and allow the embryos to capture particles and direct them towards the mouth. Viable

TABLE 2

\section{TIMING OF POST-CLEAVAGE DEVELOPMENT OF C. NAVICELLA AT AMBIENT LAB TEMPERATURE $\left(20-22^{\circ} \mathrm{C}\right)$}

\begin{tabular}{|c|c|c|}
\hline $\begin{array}{l}\text { Time (days } \\
\text { post-laying) }\end{array}$ & $\begin{array}{c}\text { Percent } \\
\text { Development }\end{array}$ & Stage \\
\hline 1 & $5 \%$ & Early cleavages complete \\
\hline 2 & $10 \%$ & Gastrulation by epiboly begins \\
\hline 3 & $15 \%$ & $\begin{array}{l}\text { Gastrulation complete, micromeres completely surround } \\
\text { macromeres, no ciliation }\end{array}$ \\
\hline 4 & $20 \%$ & $\begin{array}{l}\text { Stomodeum begins to form, very early sporadic ciliation } \\
\text { beginning, "raspberry" }\end{array}$ \\
\hline 6 & $30 \%$ & Elongation begins; ciliation apparent, "potato" \\
\hline 7 & $35 \%$ & $\begin{array}{l}\text { Pre-veliger with head-foot anlage visible; earliest differentiation of } \\
\text { viable embryos from nutritive embryos }\end{array}$ \\
\hline 9 & $45 \%$ & $\begin{array}{l}\text { Early "head vesicle" veliger; eyespots present, beginning to } \\
\text { ingest nutritive embryos }\end{array}$ \\
\hline 15 & $75 \%$ & $\begin{array}{l}\text { Veliger; ingesting nutritive embryos with gusto, } \\
\text { able to ingest whole or particulate embryos (yolk granules) }\end{array}$ \\
\hline 18 & $90 \%$ & $\begin{array}{l}\text { Late stage veliger with large propodium, velum; } \\
\text { most to all nutritive embryos gone }\end{array}$ \\
\hline 20 & $100 \%$ & Juvenile; velum resorbed; all nutritive embryos gone \\
\hline$\sim 21$ & & $\begin{array}{l}\text { Hatching of crawl-away juveniles takes place over the course of a } \\
\text { few days; juveniles dependent on maternal action for hatching } \\
\text { and will not hatch on their own in still culture dish if removed from } \\
\text { mother }\end{array}$ \\
\hline
\end{tabular}

Times indicated are averages of multiple broods from several females. embryos are heavily ciliated, and use the ciliated velum, foot, and head vesicle to move particulate yolk and nutritive embryos towards the mouth. Velar cilia create currents within the capsule, and are also able to catch particles as in planktotrophic larvae.

\section{Intracapsular feeding}

Nutritive embryos can be ingested in one of two ways. Most frequently, nutritive embryos are broken down and ingested as yolk granules, which range from 14 to $46 \mu \mathrm{m}$ in size ( $n=33$ granules), which are carried along the velum towards the mouth. Viable embryos are frequently seen with their mouths and food groove full of yolk particles (Fig. 3A). Movement of viable embryos against each other and the walls of the capsule, and even the pumping of the exposed heart, may aid in breaking down nutritive embryos, as though bursting a balloon, although nutritive embryos in isolated cultures lose the outer ectoderm and produce yolk granules without this assistance. Viable embryos often hold whole nutritive embryos behind the head vesicle or velar lobes. Nutritive embryos are also swallowed whole; the large, trough-shaped mouth is able to expand to accommodate their large size (Fig. 3B-B").

By day 18 , the majority of nutritive embryos have been ingested. Metamorphosis takes place within the capsule, and is marked by the resorption of the velum and loss of the operculum (Fig. 2D). Around this time, the mouth changes from trough-shaped to narrowed, with "lips" that extend beyond the mouth (Fig. 2D). Any nutritive embryos remaining in capsules are not eaten after this point. Ingested yolk is not all digested until later in development or even after hatching.

A dozen embryos identified as viable 8 days after laying were reared for approximately one week without access to nutritive embryos. These embryos produce a shell of similar size to embryos with access to nutritive embryos, but show reduced body mass, and resemble "empty" embryos as described by Smith and Thatje (2013). No attempt was made to rear these individuals to metamorphosis.

Gills begin to grow around day 16, and by the time of hatching, juveniles have 5 or 6 gills. Encapsulated embryos do not hatch on their own in still culture; however, capsules will rupture if disturbed. When brooded, mothers control the time of hatching, which can take place over a period from hours to days. Hatching size was not measured in this study, as embryos were not hatched naturally, but hatching shell length of $C$. navicella has been reported as $966.54 \mu \mathrm{m}\left(23^{\circ} \mathrm{C}, \mathrm{SE}=10.08 \mu \mathrm{m}, \mathrm{n}=1692\right.$ individuals) (Collin and Spangler 2012). Hatched juveniles are highly motile and will strand themselves above the water line in culture dishes, resulting in high mortality. Hatching juveniles typically retain large yolk-stores, and large quantities of yolk are frequently visible within the gut of late-stage viable embryos (Fig. 2D). Immediately after hatching, 


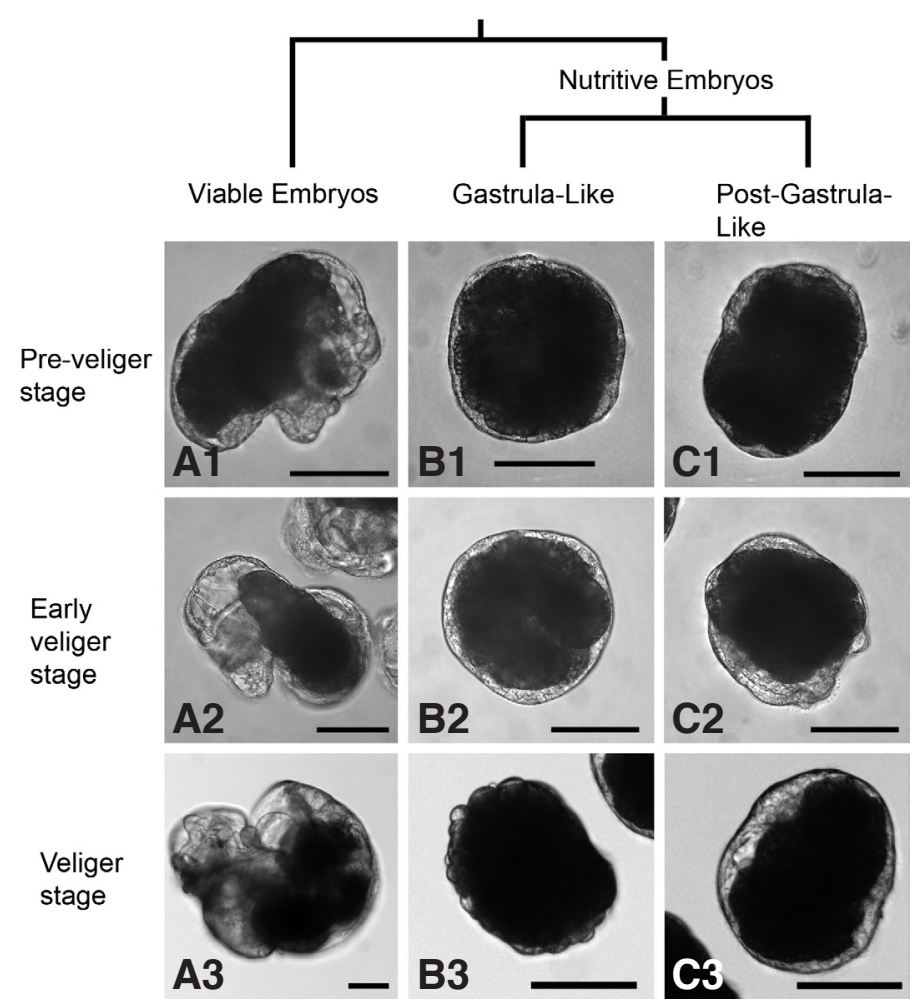

juveniles reared with Isochrysis galbana in clean glassware are not observed with food other than yolk in the gut, and suffer high mortality, while those reared with Isochrysis galbana in biofilmed glassware survive well, indicating grazing on biofilm may play an important role at this stage.

\section{Development of nutritive embryos: gastrula-like embryos}

There are no obvious morphological features that distinguish nutritive embryos at early cleavage stages, and they are not readily distinguished from viable embryos until after differentiation begins (Fig. 4). Nutritive embryos of $C$. navicella arrest development shortly after gastrulation (Fig. 4A). Only when viable embryos begin to show organ differentiation can nutritive embryos be identified with certainty. In all cases, nutritive embryos can be distinguished from viable embryos by their delayed rate of differentiation relative to viable embryos, lack of growth, and overall lack of differentiation. At this earliest point of distinction, they can be visually classified into two distinct morphological categories: gastrula-like nutritive embryos and post-gastrula-like nutritive embryos. To confirm the existence of two distinct morphological classes of nutritive embryos, we characterized and measured all nutritive embryos in a single capsule ( $n=171$ nutritive embryos). At the earliest stage of differentiation, gastrula-like nutritive embryos do not have cilia, while post-gastrula-like embryos do. Gastrula-like nutritive embryos have

Fig. 5. Nutritive embryos can be distinguished into two categories based on morphology. Ratio of yolk area to total embryo area (A, C, E) and embryo roundness (B, $\mathbf{D}, \mathbf{F})$ divides nutritive embryos into two distinct populations. Counts (A, B) were transformed into density plots (C, D) to visualize phenotype independent of binning. Individual density plots $(\mathbf{E}, \mathbf{F})$ confirm that the two populations separate based on the proposed categories of gastrula-like and post-gastrula-like nutritive embryos.
Fig. 4. Nutritive embryos of $C$. navicella can be categorized as gastrulalike and post-gastrula-like nutritive embryos during development. Nutritive embryos do not complete development, but arrest at different developmental timepoints. Rows (numbered) are embryos from the same capsule. Columns (letters) represent the different embryo types. At the pre-veliger stage, (A1) viable embryos can be distinguished from (B1) gastrula-like nutritive embryos and (C1) post-gastrula-like nutritive embryos. At the early veliger stage, embryos continue to be categorized as (A2) viable embryos, (B2) gastrula-like nutritive embryos and (C2) postgastrula-like nutritive embryos. At the veliger stage, (A3) viable embryos are much larger, (B3) gastrula-like nutritive embryos have lost their outer epithelium, and (C3) post-gastrula-like nutritive embryos show elongation and extrusion of some cells.

a significantly higher ratio of yolk to embryo area (mean gastrulalike $=0.839$, mean post-gastrula-like $=0.744$, t-test, $\mathrm{p}<0.0001$ ), and greater roundness (4(Area) / MMajor Axis) $^{2}$ ) (mean gastrulalike $=0.922$, mean post-gastrula-like $=0.886$, t-test, $\mathrm{p}<0.0001$ ). Histograms show that the two populations differ and overlap in both characters (Fig. $5 \mathrm{~A}, \mathrm{~B}$ ). Density plots, which are not dependent on bin size, show two distinct peaks for the two characters measured (Fig. 5 C,D). These peaks correspond to density plots of the two types of nutritive embryos described (Fig. 5 E,F).

Gastrula-like nutritive embryos arrest development shortly after gastrulation (Fig. 4B1, B2, B3). They do not show ciliation, they have a tightly packed central ball of yolk with a surrounding outer layer of epidermal cells (Fig. 5E), are round in shape (Fig. 5F), and
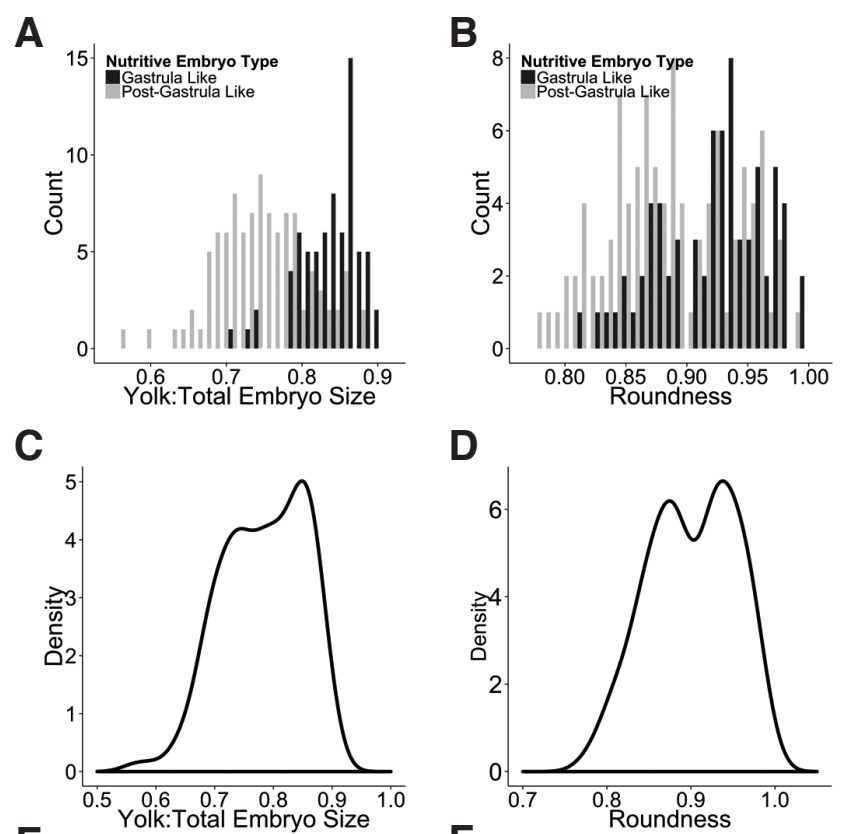

E

D
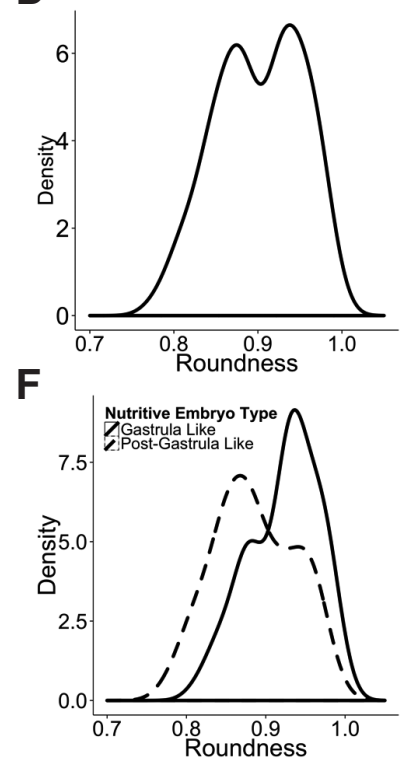

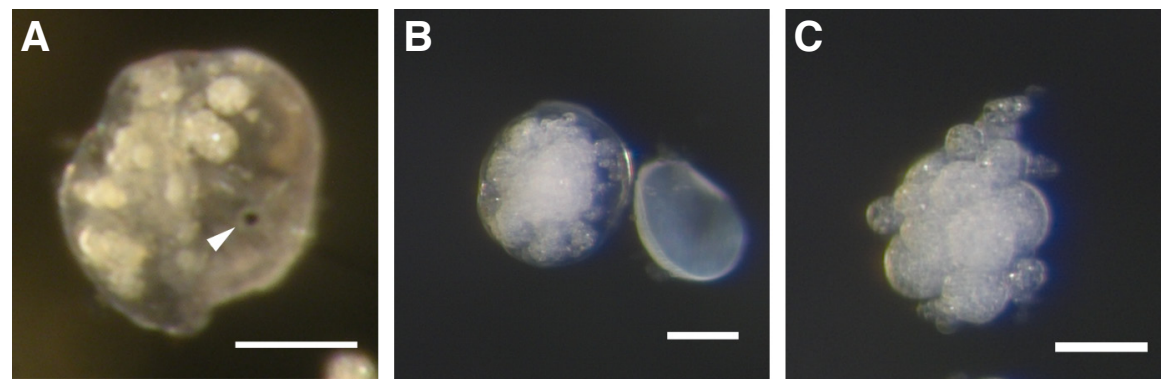

Fig. 6. Nutritive embryo differentiation in C. navicella. Post-gastrula-like nutritive embryos sometimes have recognizable structures such as (A) eyespots (indicated by arrowhead). After four days in culture, post-gastrula-like embryos (B) maintain the outer ectoderm for a longer period and may show differentiation including growth of shell cap, while (C) gastrula-like nutritive embryos fragment. Scale bars, $100 \mu \mathrm{m}$.

closely resemble gastrulae (compare Fig. 4B1 with Fig.1K). When gastrula-like nutritive embryos are reared in isolated culture (three capsules from each of two females), they break down rapidly. Within two days the internal yolk forms granules, followed by the disappearance of the external epithelium. Eventually, most gastrula-like nutritive embryos will lose the outer epithelium, becoming clumps of yolk globules that can be maintained in culture for a few days (Fig. 4B3, 6C). A subset of these gastrula-like nutritive embryos continue to elongate, but within 3-4 days all gastrula-like nutritive embryos degraded in culture.

\section{Development of nutritive embryos: post-gastrula-like embryos}

Post-gastrula-like embryos arrest at a later developmental stage than gastrula, and are highly abnormal in comparison with viable embryos (Fig. 4 C1, C2, C3). Unlike viable embryos, they do not increase greatly in size, and although they show limited differentiation, they are disorganized, often asymmetric, and irregular in shape. They are highly variable in morphology, and show various defects as described below. These embryos can be distinguished from gastrula-like nutritive embryos by their less rounded shape (Fig. 5F) and the presence of ciliation. The central concentrations of yolk are often apposed to the outer layer of epidermal cells on one side, and there is more space between the yolk and the outer epithelium (Fig. 5E). Post-gastrula-like nutritive embryos are able to turn within their capsules and in a petri dish, and have dense patches of longer cilia scattered across the embryo. Post-gastrulalike embryos show minor differentiation, including outgrowths of cells that resemble the absorptive cells (sometimes referred to as embryonic kidneys) of viable embryos (Fig. 7B). These cells are autofluorescent in nutritive embryos (Fig. 7B'), as are the embryonic kidneys in viable embryos (Fig. $7 \mathrm{~A}, \mathrm{~A}^{\prime}$ ). Autofluorescence of the absorptive cells has also been reported in $C$. fornicata (Lyons et al., 2012). Post-gastrula-like embryos also show ciliated outgrowths of cells, thickened epidermal cells, and infrequently grow eyespots (Fig. 6A) or shell caps (Fig. 6B). When grown in isolation as described above, post-gastrula-like embryos remain relatively unchanged in size (mean diameter $=184.6 \mu \mathrm{m} \pm 13.83 \mathrm{SD}, \mathrm{n}=$ 5). Within several days, they also show internal yolk vesiculation, but take longer to break down than gastrula-like nutritive embryos. Post-gastrula-like nutritive embryos can be maintained successfully in culture for more than a week (Fig. 6B).

Within capsules, globules of yolk are often present, presumably as a result of nutritive embryo breakdown. At the earliest point that nutritive embryos can be distinguished from viable embryos, the proportion of gastrula-like nutritive embryos and post-gastrula-like nutritive embryos is similar (Fig. 8). As development proceeds, a higher proportion of post-gastrula-like embryos are seen within the capsules, but whether this is due to preferential feeding on gastrula-like nutritive embryos, more rapid breakdown of gastrulalike nutritive embryos, or by continued development of gastrula-like nutritive embryos into post-gastrula-like nutritive embryos is unclear.

\section{Timing of early cleavages: C. navicella and C. lessoni}

Early differences in developmental timing may lead to differences in later developmental rates. For example, early differences in cleavage timing translated into differences in onset of subsequent developmental stages in the abalone Haliotis asinina (Jackson et al., 2012). Developmental timing is also known to be a genetically controlled trait in the fly, Drosophila melanogaster, although faster developmental time results in reduced life expectancy (Chippindale et al., 1997). Timing of the first two cleavages of $C$. navicella was compared to those of the co-occuring planktotrophic developer, C. lessoni. As there is little variability in developmental outcome (i.e. all embryos produce viable larvae) in $C$. lessoni, it was used as a control. Analysis of video images shows that timing of the first two cleavages of $C$. lessoni are synchronous within a capsule as measured by the coefficient of variation $\left(\mathrm{CV}_{\text {first cleavage }}=3.82 ; \mathrm{CV}_{\text {second }}\right.$ cleavage $=2.53$ ), while embryos of $C$. navicella are less synchronous $\left(\mathrm{CV}_{\text {first cleavage }}=17.91 ; \mathrm{CV}_{\text {second cleavage }}=8.32\right)$ (Fig. 9). Cleavage
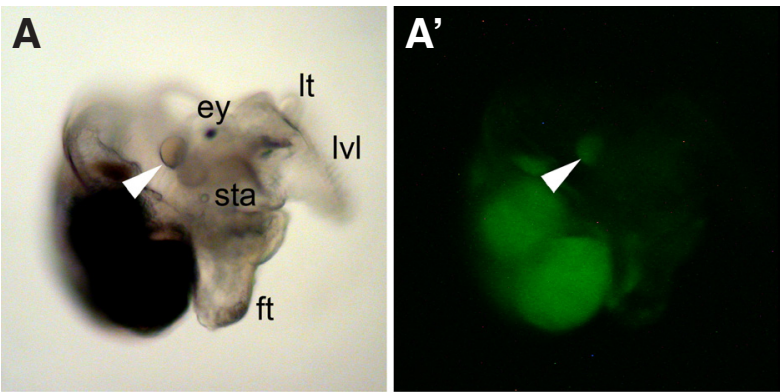

B

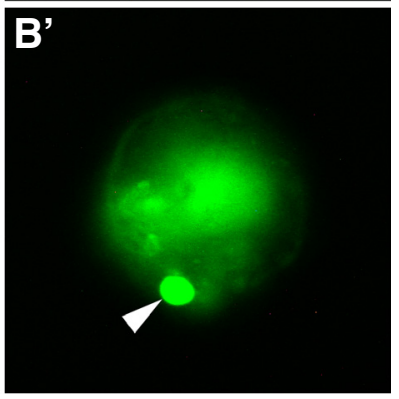

Fig. 7. Autofluorescent cells present in viable embryo are also found in some nutritive embryos. Absorptive cells (A) in viable embryos autofluo-

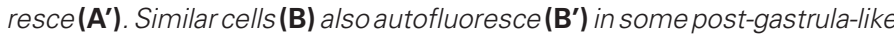
embryos. Arrowheads indicate autofluorescent cells. Abbreviations: ey, eyespot; ft, foot; It, left tentacle; IVl, left velar lobe; sta, statocyst. 


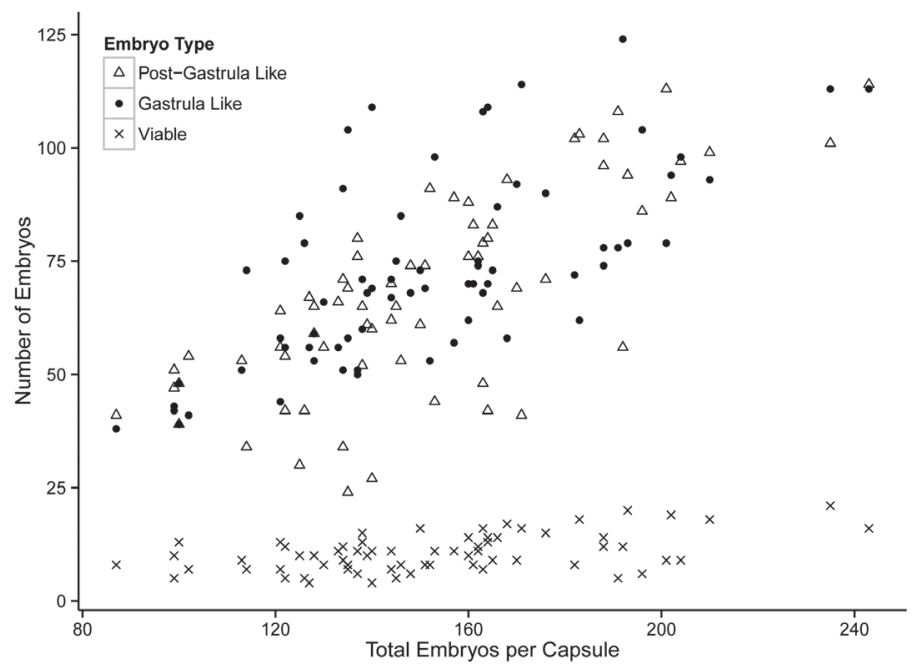

Fig. 8. Counts of embryos per capsule of $C$. navicella, at the earliest point that nutritive embryos can reliably be differentiated from viable embryos. Embryos from 68 capsules were counted from 18 different females after approximately 7 to 8 days of development.

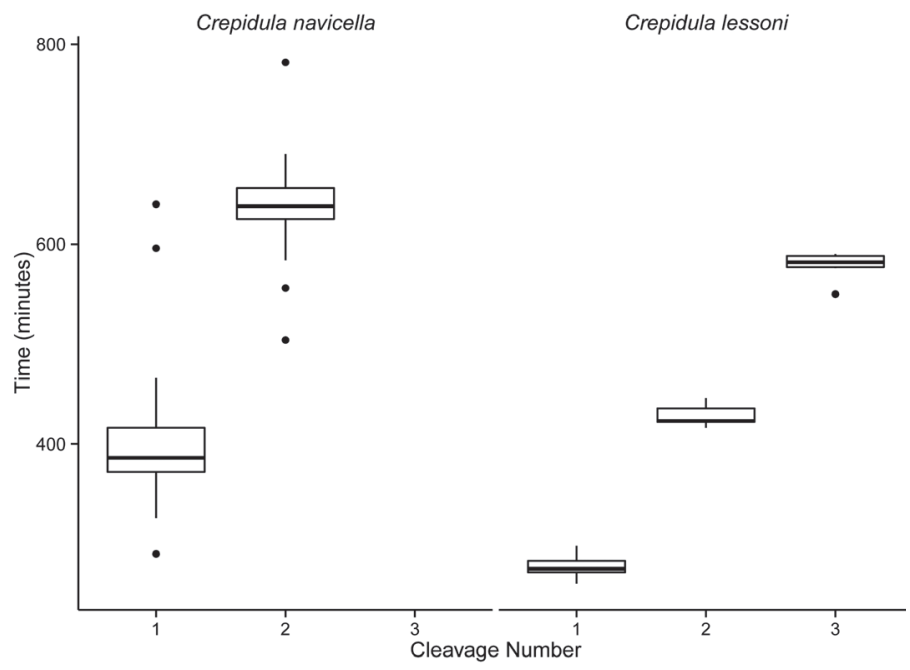

Fig. 9. Box and whisker plots showing a larger range of relative cleavage times in the adelphophagic $\boldsymbol{C}$. navicella than the planktotrophic C. lessoni. The heavy central line represents the mean, upper and lower lines represent 25 and $75 \%$ intervals, and whiskers are $1.5 x$ the interquartile range (IQR). Points indicate values falling outside the whiskers. Time zero indicates beginning of recording. At least ten embryos of each species were tracked.

times for $C$. navicella are also slower than for $C$. lessoni, although temperature was not controlled in this case. Embryos that were first to complete first cleavage were also usually first to complete second cleavage.

\section{Discussion}

Female $C$. navicella produce a small number of viable embryos and a large number of nutritive embryos that develop abnormally and serve as a source of nutrition for the viable embryos. We have shown: (1) that nutritive embryos can be divided into two broad categories based on morphology; gastrula-like nutritive embryos and post-gastrula-like nutritive embryos; (2) that nutritive embryos cannot be distinguished from viable embryos until around day 7 or 8, when organ differentiation begins in viable embryos; and (3) that the timing of early cleavage is highly variable, and is more variable than in $C$. lessoni, a planktotrophic developer in which all embryos in a capsule are expected to develop and hatch as larvae.

\section{Nutritive embryo development in C. navicella represents alternative developmental phenotypes}

An important function of nutritive embryos is that they allow for increased embryo size without increasing egg size. Increased embryo size correlates with increased juvenile size, which is thought to increase post-metamorphic survival (Smith and Fretwell 1974; Marshall and Keough 2007; but see Jacobs and Sherrard 2010). Nutritive embryo provisioning does not necessarily produce juveniles that are larger than those produced by large eggs, but does increase variation in hatchling size compared to non-adelphophages, which may be adaptive (Spight 1976; Rivest 1983; Collin and Spangler 2012). In C. navicella, the number of viable embryos per capsule is fairly constant, while the number of nutritive embryos varies greatly (Fig. 6). This produces a range of offspring sizes, which may be an adaptation to seasonal environmental variation that hatchlings are exposed to, similar to that seen in other gastropods that produce embryos throughout the year (Rivest 1983).

All embryos of $C$. navicella appear to begin their development in the same way, but will become either viable or nutritive embryos. At approximately 7-8 days after laying, the distinction between viable and nutritive embryos becomes evident, and nutritive embryos can be further distinguished by morphology into two classes: gastrulalike and post-gastrula-like nutritive embryos. Characters including presence or absence of cilia, degree of embryo roundness, and the ratio of yolk to embryo area all support the categorization of nutritive embryos into these two classes. This suggests that the three types of embryos described here represent alternative developmental outcomes within $C$. navicella, produced from the same genome by developmental switches. These switches leading to the differences in developmental outcomes in embryos of $C$. navicella may largely be under genetic or environmental influence or some combination of the two.

The existence of gastrula-like and post-gastrula-like nutritive embryos may function to enhance feeding ability in viable embryos. We observed that gastrula-like embryos tend to fragment into yolk granules, whereas post-gastrula-like embryos tend to stay intact. Viable embryos may feed on smaller yolk granules during early development, while later in development expand their feeding to include the larger intact post-gastrula-like embryos. Indeed we observed that early in development, just after viable embryos begin to show signs of differentiation, yolk granules can be seen in the stomodeum, Later in development, however, viable embryos are capable of feeding on both yolk granules or whole embryos. This is consistent with observations in Lirabuccinum dirum that preferentially feed on a specific nutritive embryo morphology that provides a "handle" for the stomodeum to grasp (Rivest 1983), as well as in the vermetid gastropod Vermetus triquetus that feeds preferentially on blastulae-type nutritive embryos (Calvo and Templado 2004). Finally, gastrula-like and post-gastrula-like embryos may have additional functions. For example, post-gastrula-like 
embryos may function to prevent capsules from becoming fouled - if too large a concentration of yolk granules and disintegrating yolk material are present within a capsule, viable embryos may become damaged.

Together, these results suggest that gastrula-like and postgastrula-like nutritive embryos result from disruptions at different points in the developmental network that result in alternative developmental phenotypes. If this were a neutrally evolving trait, we would expect high levels of continuous variance in both the distribution and the phenotype of nutritive embryos (Abouheif 2004). However, the variability is restricted to two classes in $C$. navicella suggesting that nutritive embryo morphology is under selection, and thus, is likely to be an evolved, adaptive trait. This is similar to the disruption of developmental networks that occurs in other cases of polyphenic development (Abouheif and Wray 2002). Further investigation of the molecular developmental basis for these morphological differences will provide a better understanding of how development has been disrupted.

\section{Potential mechanisms underlying polyphenic development of nutritive embryo development}

The mechanisms that differentiate nutritive from viable embryos, as well as different classes of nutritive embryos are unknown. In embryos of the spiralian models Ilyanassa obsoletaand $C$. fornicata, there is asymmetric localization of various RNA transcripts during early cleavages (Kingsley et al., 2007; Henry et al., 2010b; Chan and Lambert 2011). mRNAs are differentially localized to specific daughter cells during cleavage via the centrosome (Lambert and Nagy 2002). This specific mRNAlocalization has been shown to play an important role in downstream differentiation events (Rabinowitz and Lambert 2010). Therefore, the disruption of correct segregation of developmental determinants could potentially play a role in nutritive embryo development. Such disruptions in determinant localization could be mediated by subtle differences in cleavage timing via this centrosomal segregation mechanism. If the final patterning of determinants were not identical, a variety of nutritive embryo types could be produced. Lability in adelphophagic development may also reflect the multiple developmental pathways that can be disrupted to produce the alternate developmental phenotype of nutritive embryos, as compared to the seemingly straightforward pathway that leads to the production of direct-developing juveniles from large eggs (Collin and Spangler 2012). Collin (2004) found that direct development with nutritive embryos was less phylogenetically constrained than direct development from large eggs, further supporting the idea that adelphophagic development is evolutionarily labile, and suggesting that this plasticity in development can be acted on by selective forces.

If interruptions are occurring early in development due to differences in allocation or localization of maternal determinants during early cleavage, we should see some differences early in development. Indeed, we observed high variation in the timing of early cleavages. Although they are indistinguishable morphologically, early cleavages of $C$. navicella are not synchronous within a capsule. Differences in fertilization timing may account for this variation in cleavage timing within a capsule. However, cleavage in the broadcast spawner, Haliotis asinina, is variable as early as third cleavage in full siblings that have been fertilized at the same time (Jackson et al., 2012). Early variation in the timing of third cleavage (complete within 15 minutes) correlates with later variation in timing of hatching from the vitelline envelope (complete within 60 minutes), as well as later developmental markers including shell development and metamorphosis, and does not appear to be due to variation in egg size, which is minimal (Jackson et al., 2012). Other Crepidula species that produce planktotrophic larvae typically show synchronous development within a capsule, although not necessarily among capsules, which is not unexpected due to the time it takes for females to produce individual capsules. For example, cleavage of the planktotrophic $C$. fornicata has been reported to be synchronous (Henry et al., 2010a), and the planktotrophic $C$. lessoni is shown here to have synchronous early cleavages. Species with nutritive embryos have previously been reported to have asynchronous development within capsules, although details of the degree of synchrony are lacking (Hoagland 1986). These differences in synchronicity between planktotrophic and adelphophagic developers suggest an early point of distinction between viable and nutritive embryos. Fast-cleaving embryos may develop faster overall, allowing them to overtake and ingest nutritive embryos. Fast-cleaving embryos may even be able to signal to their capsule mates to arrest their development. It has been suggested that nutritive embryo determination is controlled by inter-embryonic interactions, rather than maternal determinants, particularly in cases where only a single viable embryo will emerge from the capsule (Hadfield 1989), a possibility that warrants further exploration.

\section{Nutritive embryo development is evolutionarily labile}

Although development via feeding on nutritive embryos is well known in gastropods, relatively few are known to feed on gastrula-like nutritive embryos or more developed embryos. Other adelphophagic calyptraeids produce either non-cleaving nutritive eggs (Gallardo 1977; Gallardo and Garrido 1987); nutritive embryos that cleave a limited number of times such as Crucibulum auricula, in which nutritive embryos undergo maximally four cleavages (Miloslavich and Penchaszadeh 2001); or nutritive embryos that cleave and gastrulate, similar to those described here (Veliz et al., 2003; Veliz et al., 2012). Sibling cannibalism also takes place (Veliz et al., 2001; Miloslavich et al., 2003), or nutritive egg feeding followed by sibling cannibalism (Miloslavich and Penchaszadeh 2001; Veliz et al., 2001). This has been termed complex adelphophagy (Strathmann and Strathmann 2006). The known distribution of cleaving and non-cleaving nutritive embryo development in the calyptraeids is summarized by Collin (2003a). In other gastropods, adelphophagy is found mainly in muricids, buccinids, and vermetids (Fioroni 1988). Extra-embryonic provisioning in these groups is similarly diverse, ranging from non-cleaving eggs, or nutritive eggs limited to a few abnormal cleavages (Rivest 1983; West 1983; Gallardo and Garrido 1987; Stöckmann-Bosbach 1988; Güler and Lök 2013; Smith and Thatje 2013), to sibling cannibalism and complex adelphophagy (Calvo and Templado 2004; Strathmann and Strathmann 2006). The lability observed in nutritive embryo development, both within C. navicella and among adelphophages in general, suggests that the mechanisms which underlie this mode of development are different, and that development can be disrupted in many ways, while still leading to the same functional phenotype.

\section{Conclusions}

Asynchrony in early cleavage timing and later differences in 
nutritive embryo morphology suggests that development in $C$. navicella can be considered as an alternative developmental phenotype, making this a useful point of comparison to other organisms that produce nutritive embryos, and more broadly, to other taxa that produce alternative developmental phenotypes. The repeated evolution of nutritive eggs and embryos in the calyptraeids suggests that nutritive eggs and embryos can be produced by a variety of means, and can be considered a natural experiment in embryonic disruption. The pattern of repeated development of similar phenotypes by different mechanisms has been observed in vertebrates and invertebrates, and is known as developmental system drift (True and Haag 2001; Abouheif and Wray 2002; Félix 2005; Nahmad et al., 2008). Therefore, elucidating the developmental and evolutionary basis of viable and nutritive embryos in the calyptraeid gastropods can contribute to our understanding not only of normal spiralian development, but of general patterns in evolution.

\section{Materials and Methods}

\section{Study species}

We carefully evaluated the taxonomic status of individuals used in this study, and identified them as Crepidula navicella (Lesson 1831) by comparison with the original holotype in the Muséum National d'Histoire Naturelle, Paris (holotype MNHN 27117). This shell, collected from the tropical coast of Peru, was figured by Hoagland (1983), who concluded that $C$. navicella was most likely a valid species. The shell of this species can be identified by the flat tan shell, absence of muscle scars, white shelf with sinusoidal margin and shaggy brown periostracum (not present in the type, which is somewhat beach-washed). Like its close relative Crepidula onyx, this species has a striped mantle margin (Fig. 1A). Information on Crepidula navicella has been previously published under the name "Crepidula aff. onyx" (Collin, 2003 b,c). DNA sequences are available in GenBank (AF546020, AF545954, AF545877) and vouchers from these previous publications are available at the Field Museum of Natural History (FMNH299420). A review of calyptraeid development (Hoagland, 1986) referred to this species as $C$. cerithicola, and Collin (2003a) followed this taxonomy before changing to $C$. aff. onyx. Molecular phylogenetic analysis and comparisons with the types clearly indicate that $C$. cerithicola is distinct from $C$. navicella. In subsequent experimental studies of sex change and the effects of temperature on offspring size (Collin et al., 2005; Collin and Spangler 2012) C. navicella was referred to as Crepidula cf. onyx.

\section{Collection and maintenance of adults and embryos}

Adult specimens were collected from Playa Venado, Veracruz, Panama $\left(8.886^{\circ} \mathrm{N}, 79.596^{\circ} \mathrm{W}\right)$ where they are found on the sides and bottoms of rocks and cobble in the low intertidal. Adults were gently pried from the rocks and kept in seawater for transport back to the lab. If females were found to be brooding, egg masses were collected with fine forceps and placed in Eppendorff tubes containing $0.22 \mu \mathrm{m}$-filtered seawater, and placed with their mothers in $50 \mathrm{~mL}$ falcon tubes filled with seawater. Animals were returned to the lab in soft-sided coolers containing freezer-packs in order to keep the animals cool during transport.

Adults and embryos were maintained at Naos Island Laboratories (STRI) in coarse-filtered, UV sterilized seawater at room temperature $\left(20-22^{\circ} \mathrm{C}\right)$. Following Collin and Salazar (2010), animals were kept in medium sized plastic cups in approximately $400 \mathrm{ml}$ of seawater. Water was changed daily for the first week and three to four times per week thereafter. Animals were fed $5 \times 10^{4}$ cells per $\mathrm{ml}$ of Isochrysis galbana daily.

\section{Embryonic cultures}

Field collected broods were rinsed several times and cultured in small petri dishes in $0.22 \mu \mathrm{m}$ filtered seawater containing $6.3 \times 10^{-5} \mathrm{M}$ streptomy- cin salt and $1.4 \times 10^{-4} \mathrm{M}$ penicillin $\mathrm{G}$ potassium salt. Clutches laid in lab are easily seen (Fig. 1A) and can be collected by gently prying females from the sides of the cups. For developmental observations, embryos were left in their capsules. When stages of interest were reached, capsules were opened with fine watchmakers forceps. Embryos were readily cultured outside their capsules using gelatin-coated petri dishes in $0.22 \mu \mathrm{m}$ filtered seawater with minimal antibiotic concentrations. Water was changed daily on cultured embryos.

\section{Microscopy}

General observations of development were made using a Nikon SMZ 1500 stereomicroscope equipped with a Nikon Coolpix S4. More detailed observations were made using a Nikon E600 compound microscope equipped with epifluorescence. Images were captured using either a Nikon Coolpix 995 camera or a Digital Microscope Camera ProgRes C14 Plus (Jenoptik). Comparisons of development between nutritive and viable embryos were made within capsules to reduce variation introduced by differences in timing of capsule production. In order to observe sufficient numbers of embryos, developmental observations were made from embryos reared at ambient temperature $\left(20-22^{\circ} \mathrm{C}\right)$.

Two different methods were used to measure cleavage times. In order to measure cleavage times accurately, absolute cleavage times reported in Table 2 were calculated from time-lapse images of encapsulated embryos held at constant humidity and temperature $\left(28^{\circ} \mathrm{C}\right)$ using a Zeiss Axiovert 200M, equipped with a 100-XL incubation chamber, including heated stage and humidifier attachments. The heated stage was unable to maintain lower temperatures. Images were captured with an attached Zeiss Axiocam HRm camera running Axiovision ver. 4.8 software, and adjusted for brightness and contrast using Photoshop CS3 (Adobe). Capsules were not opened, and were placed in small petri dishes with filtered seawater containing antibiotics. Unopened capsules were held in place under a glass coverslip supported with plasticine feet. This also maintained the position of a large number of embryos during image capture. Multiple embryos were imaged at the same time, and 10 individual embryos from time-lapse images were tracked manually to calculate cleavage times.

In order to test the variability in rates of early cleavage, timing of the first two cleavages of $C$. navicella were compared to those of the planktotrophic developer, Crepidula lessoni, where all embryos develop normally and hatch as free-swimming larvae. Relative cleavage times were measured from single capsules of both species placed in fingerbowls of $0.22 \mu \mathrm{m}$ filtered seawater and viewed with the Nikon SMZ 1500 stereomicroscope. Using the timelapse function, one image per minute was captured with a Nikon Coolpix S4. The resulting videos were compared by importing the video frames to layers, and converting those layers to separate image files in Photoshop CS3 (Adobe). Frame number was converted to time in minutes. At least 10 embryos from a single capsule of each species were tracked and the frame number noted for first and second cleavages.

\section{Morphological analysis of nutritive embryos}

In order to distinguish between the classes of nutritive embryos reported here, single images of live embryos from one full capsule of one female were taken using a Zeiss Axiolmager.Z1 microscope. Embryos were categorized as being either gastrula-like or post-gastrula-like during collection, and ciliation was noted as being present or absent during imaging. Viable embryos were excluded from the analysis. Embryo images were processed using Image J64 (1.48v). The outer boundary of each embryo and internal yolk boundary were outlined free-hand and measured using included shape descriptors. The ratio of inner yolk area to total embryo area was calculated. The two proposed classes of nutritive embryo were compared using roundness and yolk:total area ratios, and Welch two-sample t-tests performed. Histograms and density plots were produced using the ggplot2 package in $\mathrm{R}$ (version 3.1.0).

\section{Acknowledgements}

Thank you to members of the Collin lab who have provided assistance 
with collection and maintenance of animals. Thanks also to members of the Abouheif lab and to an anonymous reviewer for providing valuable comments on the manuscript. This work was supported by the Smithsonian Tropical Research Institute and NSF grant IOS-1019727 to RC, and the Canada Research Chairs program and Natural Sciences and Engineering Research Council of Canada to EA.

\section{References}

ABOUHEIF, E and WRAY, G A (2002). Evolution of the gene network underlying wing polyphenism in ants. Science 297: 249-252.

ABOUHEIF, E (2004). Aframework for studying the evolution of gene networks underlying polyphenism: Insights from winged and wingless ant castes. In Environment, development, and evolution: Toward a synthesis (Eds B K Hall, R D Pearson, and G B Müller). MIT Press, Cambridge, pp.125-137.

CALVO, M and TEMPLADO, J (2004). Reproduction and development in a vermetid gastropod, Vermetus triquetrus. Invertebr Biol 123: 289-303.

CHAN, X Y and LAMBERT, J D (2011). Patterning a spiralian embryo: A segregated RNA for a Tis 11 ortholog is required in the $3 \mathrm{a}$ and $3 \mathrm{~b}$ cells of the llyanassa embryo. Dev Biol 349: 102-112.

CHIPPINDALE, A K, ALIPAZ, J A, CHEN, H-W, and ROSE, M R (1997). Experimental evolution of accelerated development in Drosophila. 1. Developmental speed and larval survival. Evolution 51: 1536-1551.

COLLIN, R (2003a). Worldwide patterns in mode of development in calyptraeid gastropods. Mar Ecol Prog Ser 247: 103-122.

COLLIN, R (2003b). Phylogenetic relationships among calyptraeid gastropods and their implications for the biogeography of marine speciation. Syst Biol52:618-640.

COLLIN, R (2003c). The utility of morphological characters in gastropod phylogenetics: an example from the Calyptraeidae. Biol J Linn Soc 78: 541-593.

COLLIN, R (2004). Phylogenetic effects, the loss of complex characters, and the evolution of development in calyptraeid gastropods. Evolution 58: 1488-1502.

COLLIN, R, CHAPARRO, O R, WINKLER, F and VELIZ, D (2007). Molecular phylogenetic and embryological evidence that feeding larvae have been reacquired in a marine gastropod. Biol Bull 212: 83-92.

COLLIN, R, MCLELLAN, M, GRUBER, K and BAILEY-JOURDAIN, C (2005). Effects of conspecific associations on size at sex change in three species of calyptraeid gastropods. Mar Ecol Prog Ser 293: 89-97.

COLLIN, R and SALAZAR, M Z (2010). Temperature-mediated plasticity and genetic differentiation in egg size and hatching size among populations of Crepidula (Gastropoda: Calyptraeidae). Biol J Linn Soc 99: 489-499.

COLLIN, R and SPANGLER, A (2012). Impacts of adelphophagic development on variation in offspring size, duration of development, and temperature-mediated plasticity. Biol Bull 223: 268-277.

CONKLIN, E G (1897). The embryology of Crepidula. J Morphol 13: 1-226.

ELGAR, M and CRESPI, B (Ed.) (1992). Cannibalism: Ecology and evolution among diverse taxa. Oxford University Press, Oxford.

FÉLIX, M-A (2005). An inversion in the wiring of an intercellular signal: evolution of Wnt signaling in the nematode vulva. BioEssays 27: 765-769.

FIORONI, P (1988). Die Prosobranchier-Entwicklung mit Nahreiern. Zool Anz 221: 201-247.

GALLARDO, C S (1977). Two modes of development in the morphospecies Crepidula dilatata (Gastropoda: Calyptraeidae) from Southern Chile. Mar Biol 39: 241-251.

GALLARDO, C and GARRIDO, O (1987). Nutritive egg formation in the marine snails Crepidula dilatata and Nucella crassilabrum. Int J Invertebr Reprod 11: 239-254.

GIBSON, G, HART, C, COULTER, C and XU, H X (2012). Nurse eggs form through an active process of apoptosis in the spionid Polydora cornuta (Annelida). Integr Comp Biol 52: 151-160.

GIBSON, R C, BULEY, K R and DOUGLAS, M E (2004). Maternal care and obligatory oophagy in Leptodactylus fallax: A new reproductive mode in frogs. Copeia 2004: 128-135.

GILBERT, S F (2006). Developmental Biology. Sinauer Associates Inc., Sunderland, MA.

GÜLER, M and LÖK, A (2013). Embryonic development and intracapsular feeding in Hexaplex trunculus (Gastropoda: Muricidae). Mar Ecol 10.1111/maec.12066.
HADFIELD, M G (1989). Latitudinal effects on juvenile size and fecundity in Petaloconchus (Gastropoda). Bull Mar Sci 45: 369-376.

HEJNOL, A, MARTINDALE, M Q and HENRY, J Q (2007). High-resolution fate map of the snail Crepidula fornicata: The origins of ciliary bands, nervous system, and muscular elements. Dev Biol 305: 63-76.

HENRY, J J, COLLIN, R and PERRY, K J (2010a). The slipper snail, Crepidula: An emerging lophotrochozoan model system. Biol Bull 218: 211-229.

HENRY, J J and PERRY, K J (2008). MAPK activation and the specification of the D quadrant in the gastropod mollusc, Crepidula fornicata. Dev Biol 313: 181-195.

HENRY, J J, PERRY, K J, FUKUI, L and ALVI, N (2010b). Differential localization of mRNAs during early development in the mollusc, Crepidula fornicata. Integr Comp Biol 50: 720-733.

HOAGLAND, K. (1983). Notes on type specimens of Crepidula (Prosobranchia: Calyptraeidae) in the Muséum National d'Histoire Naturelle, Paris. Proc Acad Nat Sci Phila 135: 1-8.

HOAGLAND, K. (1986). Patterns of encapsulation and brooding in the Calyptraeidae (Prosobranchia: Mesogastropoda). Am Malacol Bull 4: 173-183.

JACKSON, D J, DEGNAN, S M and DEGNAN, B M (2012). Variation in rates of early development in Haliotis asinina generate competent larvae of different ages. Front Zool 9: 1-9.

JACOBS, M W and SHERRARD, K M (2010). Bigger is not always better: Offspring size does not predict growth or survival for seven ascidian species. Ecology 91 3598-3608.

KHILA, A and ABOUHEIF, E (2008). Reproductive constraint is a developmental mechanism that maintains social harmony in advanced ant societies. Proc Natl Acad Sci. USA 105: 17884-17889.

KHILA, A and ABOUHEIF, E (2010). Evaluating the role of reproductive constraints in ant social evolution. Philos Trans R Soc Lond B Biol Sci 365: 617-630.

KINGSLEY, E P, CHAN, X Y, DUAN, Y and LAMBERT, J D (2007). Widespread RNA segregation in a spiralian embryo. Evol Dev 9: 527-539.

LAMBERT, J D and NAGY, L M (2002). Asymmetric inheritance of centrosomally localized mRNAs during embryonic cleavages. Nature 420: 682-686.

LESSON, R P (1831). Voyage autour du monde sur la corvette La Coquille pendant les années 1822-25. Zoologie 21: 388-400.

LYONS, D C, PERRY, K J, LESOWAY, M P and HENRY, J Q (2012). Cleavage pattern and fate map of the mesentoblast, $4 \mathrm{~d}$, in the gastropod Crepidula: a hallmark of spiralian development. EvoDevo 3: 1-26.

MARSHALL, D J and KEOUGH, M J (2007). The evolutionary ecology of offspring size in marine invertebrates. Adv Mar Biol 53: 1-60.

MILOSLAVICH, P, KLEIN, E and PENCHASZADEH, P E (2003). Reproduction of Crepidula navicula Morch, 1877 and Crepidula aplysioides Reeve, 1859 (Caenogastropoda) from Morrocoy and La Restinga Lagoon, Venezuela. Nautilus 117: 121-134.

MILOSLAVICH, P and PENCHASZADEH, PE (2001). Adelphophagy and cannibalism during early development of Crucibulum auricula (Gmelin, 1791)(Gastropoda: Calyptraeidae) from the Venezuelan Caribbean. Nautilus 115: 39-44.

NAHMAD, M, GLASS, L and ABOUHEIF, E (2008). The dynamics of developmental system drift in the gene network underlying wing polyphenism in ants: a mathematical model. Evol Dev 10: 360-374.

PERRY, J C and ROITBERG, B D (2006). Trophic egg laying: hypotheses and tests. Oikos 112: 706-714.

RABINOWITZ, J S and LAMBERT, J D (2010). Spiralian quartet developmental potential is regulated by specific localization elements that mediate asymmetric RNA segregation. Development 137: 4039-4049.

RIVEST, B R (1983). Development and the influence of nurse egg allotment on hatching size in Searlesia dira (Reeve, 1846) (Prosobranchia, Buccinidae). $J$ Exp Mar Biol Ecol 69: 217-241.

SMITH, C C and FRETWELL, S D (1974). The optimal balance between size and number of offspring. Am Nat 108: 499-506.

SMITH, H L and GIBSON, G D (1999). Nurse egg origin in the polychaete Boccardia proboscidea (Spionidae). Invertebr Reprod Dev 35: 177-185.

SMITH, K E and THATJE, S (2013). Nurse egg consumption and intracapsular development in the common whelk Buccinum undatum (Linnaeus 1758). Helgol Mar Res 67: 1-12. 
SPIGHT, T M (1976). Hatching size and the distribution of nurse eggs among prosobranch embryos. Biol Bull 150: 491-499.

STÖCKMANN-BOSBACH, R(1988). Early stages of the encapsulated development of Nucella lapillus (Linnaeus) (Gastropoda, Muricidae). JMolluscan Stud54: 181-196.

STRATHMANN, M F and STRATHMANN, R R (2006). A vermetid gastropod with complex intracapsular cannibalism of nurse eggs and sibling larvae and a high potential for invasion. Pac Sci 60: 97-108.

THORSON, G (1950). Reproductive and larval ecology of marine bottom invertebrates. Biol Rev 25: 1-45.

TRUE, J R and HAAG, E S (2001). Developmental system drift and flexibility in evolutionary trajectories. Evol Dev 3: 109-119.
VELIZ, D, GUISADO, C and WINKLER, F M (2001). Morphological, reproductive, and genetic variability among three populations of Crucibulum quiriquinae (Gastropoda: Calyptraeidae) in northern Chile. Mar Biol 139: 527-534.

VELIZ, D, WINKLER, F M and GUISADO, C (2003). Developmental and genetic evidence for the existence of three morphologically cryptic species of Crepidula in northern Chile. Mar Biol 143: 131-142.

VELIZ, D, WINKLER, F M, GUISADO, C and COLLIN, R (2012). A new species of Crepipatella (Gastropoda: Calyptraeidae) from northern Chile. Molluscan Res 32: 145-153

WEST, D L (1983). Reproductive biology of Colus stimpsoni (Prosobranchia, Buccinidae): 5. Nutritive Egg Formation. Veliger 25: 299-306. 


\section{Further Related Reading, published previously in the Int. J. Dev. Biol.}

Brachyury, Tbx2/3 and sall expression during embryogenesis of the indirectly developing polychaete Hydroides elegans Cesar Arenas-Mena

Int. J. Dev. Biol. (2013) 57: 73-83

http://dx.doi.org/10.1387/ijdb.120056ca

Stable expression of Y-box protein 1 gene in early development of the abalone Haliotis diversicolor Jun Chen, Zhi-Sen Chen, Zi-Xia Huang, Cai-Huan Ke, Jie Zhang, Yi-Xiang Zhong, Wei-Wei You and Jing Zhao Int. J. Dev. Biol. (2012) 56: 369-375

http://dx.doi.org/10.1387/ijdb.113487zc

Planarian embryology in the era of comparative developmental biology José M. Martín-Durán, Francisco Monjo and Rafael Romero Int. J. Dev. Biol. (2012) 56: 39-48 http://dx.doi.org/10.1387/ijdb.113442jm

On the origin of pattern and form in early Metazoans Frederick W. Cummings

Int. J. Dev. Biol. (2006) 50: 193-208

http://dx.doi.org/10.1387/ijdb.052058fc

Morphological evidence for a morphogenetic field in gastropod mollusc eggs S E Tyler, R D Butler and S J Kimber Int. J. Dev. Biol. (1998) 42: 79-85 http://dx.doi.org/10.1387/ijdb.9496789

Embryonic development of the shell in biomphalaria glabrata (Say) U Bielefeld and W Becker

Int. J. Dev. Biol. (1991) 35: 121-131

http://dx.doi.org/10.1387/ijdb.1768600

5 yr ISI Impact Factor $(2011)=2.959$

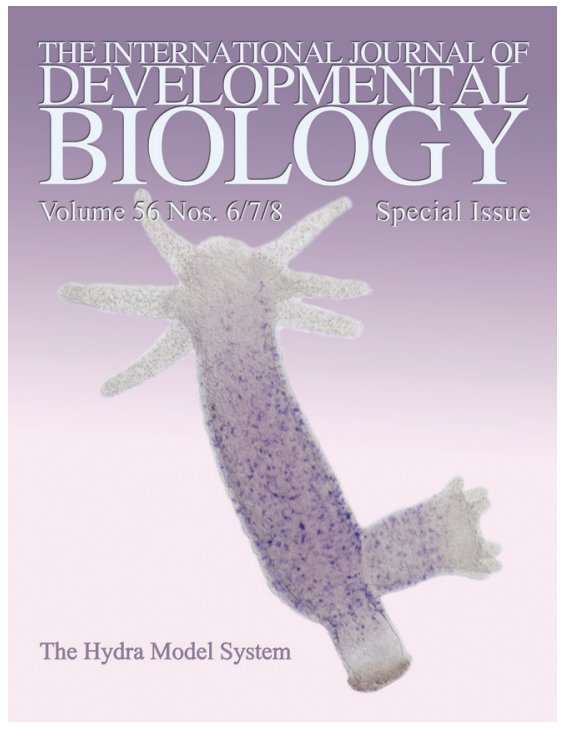

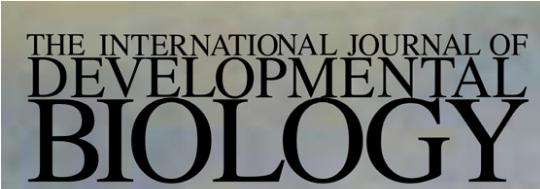

Volume 47 Nos. $7 / 8$

Special Issue

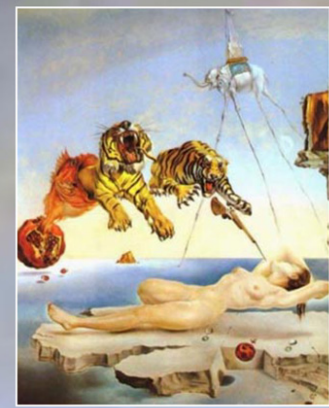

Evolution \& Development
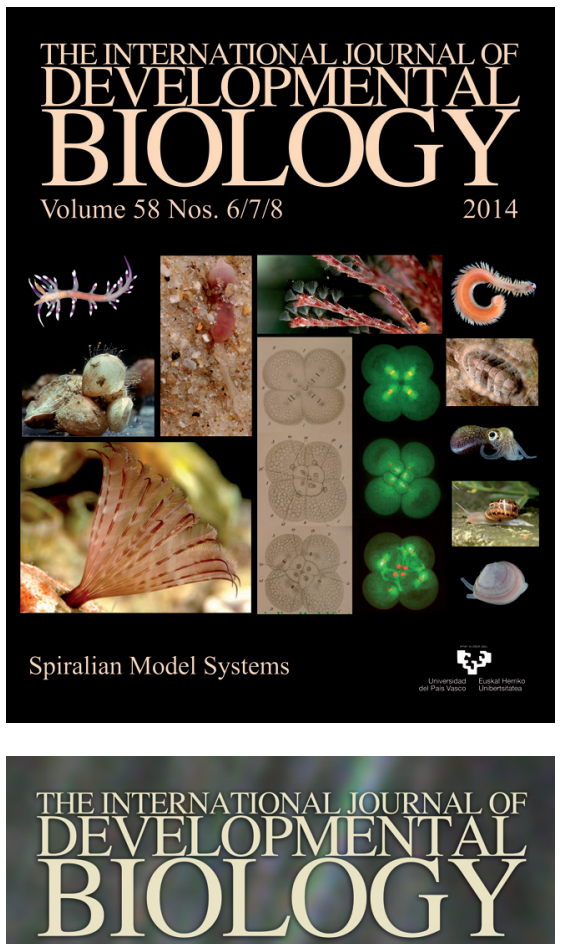

Volume 56 Nos. $1 / 2 / 3$

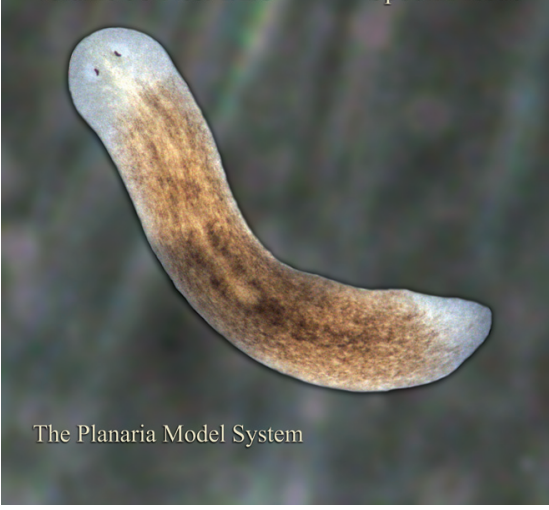

